\title{
Chemopreventive effects of fermented brown rice and rice bran against 4-(methylnitrosamino)-1-(3-pyridyl)-1-butanone-induced lung tumorigenesis in female $\mathrm{A} / \mathrm{J}$ mice
}

\author{
SUPHOT PHUTTHAPHADOONG ${ }^{1,2}$, YASUHIRO YAMADA ${ }^{1}$, AKIHIKO HIRATA ${ }^{3}$, HIROYUKI TOMITA ${ }^{1}$, \\ AYAKO TAGUCHI ${ }^{1}$, AKIRA HARA ${ }^{1}$, PORN-NGAM LIMTRAKUL $^{2}$, TERUAKI IWASAKI $^{4}$, \\ HIROSHI KOBAYASHI ${ }^{5}$ and HIDEKI MORI ${ }^{1}$
}

\begin{abstract}
${ }^{1}$ Department of Tumor Pathology, Gifu University Graduate School of Medicine, 1-1 Yanagido, Gifu 501-1194, Japan;
${ }^{2}$ Department of biochemistry, Faculty of Medicine, Chiang Mai University, Thailand; ${ }^{3}$ Division of Animal Experiment, Life Science Research Center, Gifu University, 1-1 Yanagido, Gifu 501-1193; ${ }^{4}$ Genmai Koso Co., Ltd., Nishi 1-chome, Kita 12-jo, Kita-ku, Sapporo 001-0012; ${ }^{5}$ Sapporo Cancer Seminar, 6 Odori-Nishi, Chuo-ku, Sapporo 064-0820, Japan
\end{abstract}

Received August 21, 2008; Accepted October 6, 2008

DOI: $10.3892 /$ or_00000224

\begin{abstract}
The most common cause of human lung cancer is suggested to be exposure to the carcinogens in tobacco smoke. Among the multiple chemicals in tobacco smoke, 4-(methylnitrosamino)-1-(3-pyridyl)-1-butanone (NNK) has been regarded as one of the important agents for generation of lung cancers. Previously, our studies proved that fermented brown rice and rice bran (FBRA) has chemopreventive effects against carcinogenesis of the colon, liver, stomach, bladder and esophagus. In the present study, we examined possible chemopreventive effects of FBRA on the NNK-induced lung tumorigenesis in mice. Six-week-old female A/J mice were divided into 8 groups, and groups 1-5 were given NNK (10 mmol) by i.p. injection at week 7. Groups 2 and 3 were fed with diet containing 5 and $10 \%$ FBRA during the initiation phase, respectively. Groups 4 and 5 were fed with $5 \%$ and $10 \%$ FBRA during the post-initiation phase. Groups 1 and 6 were given control diet throughout the experiment. Groups 7 and 8 were given the diet containing 5 and 10\% FBRA throughout the experiment, respectively. In both initiation (group 3) and post-initiation phase (group 5), 10\% FBRA exposure significantly reduced the multiplicity of lung tumor

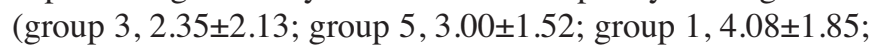
$\mathrm{p}<0.006$ and 0.04 , respectively). Furthermore, administration of FBRA during the post-initiation phase significantly
\end{abstract}

Correspondence to: Dr Yasuhiro Yamada, Department of Tumor Pathology, Gifu University Graduate School of Medicine, 1-1 Yanagido, Gifu 501-1194, Japan

E-mail: y-yamada@gifu-u.ac.jp

Abbreviations: FBRA, fermented brown rice by Aspergillus Oryzae

Key words: fermented brown rice, rice bran, lung cancer decreased the tumor size in comparison with that of control mice $(0.66 \pm 0.32$ vs. $0.77 \pm 0.33 \mathrm{~mm})$. Treatment of $10 \%$ FBRA significantly reduced the mRNA expression levels of cytochrome P450 2A5 (Cyp2a5), which is known to be closely related to the human CYP2A6 enzyme that is involved in the mutagenic activation of NNK, in the lung but not liver tissues. A significantly reduced index of Ki67 positivity of lung tumors in group 5 was confirmed when compared with tumors of the control group $(0.065 \pm 0.016$ vs. $0.114 \pm 0.025)$. These findings suggest that FBRA has inhibitory effects on NNKinduced pulmonary tumorigenesis in $\mathrm{A} / \mathrm{J}$ mice in both during initiation and post-initiation treatment, which is possibly associated with the induction of Cyp2a5 in the lung and the reduced proliferation rate of tumor cells. FBRA may be a promising chemopreventive agent for human lung cancers.

\section{Introduction}

Cancer is a leading cause of death worldwide. Lung cancer is the most common cause of cancer death, with 1.18 million deaths $(17.6 \%)$ of the world total exceeds stomach cancer (700,000 deaths) and liver cancer (598,000 deaths). However, there is limited information regarding effective agents for prevention of lung cancers. For the year 2000, about $85 \%$ of lung cancer in men and $47 \%$ of lung cancer in women is estimated to concern with tobacco smoking (1). According to the report by the International Agency for Research on Cancer (IARC), there are 55 carcinogens in tobacco smoke. Among the multiple ingredients in tobacco smoke, 20 carcinogens are likely to be involved in lung cancer induction in laboratory animals or humans. Of these, polycyclic aromatic hydrocarbons (PAHs) and a tobaccospecific nitrosamine 4-(methylnitrosamino)-1-(3-pyridyl)-1butanone (NNK) are suggested to relate to carcinogenesis $(2,3)$. NNK has been suggested to link to the etiology of lung cancer in humans as well as to the induction of tumors in commonly used rodents like rat, mouse and hamster, independently of its route of administration $(4,5)$. NNK treatment in 
$\mathrm{A} / \mathrm{J}$ mice results in the development of lung tumors that are similar to human adenocarcinoma, a representative type of human lung cancer in morphology and molecular characteristics (6-8).

Cytochrome P450 (CYP) is widely known as a family of enzymes metabolizing a variety of xenobiotics, including drugs and carcinogens. CYP plays central roles in the activation of many environmental chemicals to generate reactive intermediates (9). In vitro, enzymes from the CYP2A subfamily efficiently catalyze the metabolic activation of a number of nitrosamines, including NNK. However, the ability of each CYP2A enzyme to metabolize nitrosamines to their active forms is different from others $(10,11)$. Human CYP2A6 enzyme is known to be responsible for the metabolic activation of chemicals including nicotine (12). Indeed, Japanese male smokers with a CYP2A6 gene deletion-type polymorphism have been shown to exert reduced lung cancer risk in a hospital-based case control study $(13,14)$. In mice, function of Cyp2a5 enzyme is closely related to that of human CYP2A6 that is expressed in many tissues, including lung and liver (15).

One approach to restrain cancer incidence is a chemopreventive intervention through which the disease can be totally prevented, delayed or fixed dormant by one or more natural occurring and synthetic chemical agents. Rice is one of the major cereal foods eaten as a staple food worldwide, especially in Asian countries. Rice seeds and rice germ contain fiber and several kinds of antioxidants, such as ferulic acid (16), phytic acid (17), tocopherols and oryzanols (18). Among them, fiber and ferulic acid have been reported to prevent chemically-induced aerodigestive tract carcinogenesis in animal models (19-21). Rice germ itself or the compounds contained in the rice bran or germ have chemopreventive effects against carcinogenesis in the colon (22), liver (23), stomach (24), esophagus (25) and bladder (26) of rodents. FBRA is a processed food prepared by fermented brown rice and rice bran with Aspergillus Oryzae. It is already known that FBRA acts as a potent free radical scavenger (27). The significance of brown rice and rice germ as modulators of carcinogenesis prompted us to explore FBRA for its potential anticancer properties. In this study, we examined the chemopreventive activity of FBRA on the tobacco-derived nitrosamine (NNK)-induced lung tumorigenesis in female $\mathrm{A} / \mathrm{J}$ mice in initiation and post-initiation phases.

\section{Materials and methods}

Animals. Female A/J mice, 3 weeks of age, were obtained from Japan SLC, Inc. (Hamamatsu, Japan) and housed in wire cages ( 3 or $4 /$ cage) under controlled conditions of humidity $(50 \pm 10 \%)$, lighting (12-h light/dark cycle) and temperature $\left(23 \pm 2^{\circ} \mathrm{C}\right)$, with free access to water and were bred and maintained on a basal diet, CE-2 (CLEA Japan Inc., Tokyo, Japan), until 6 weeks of age.

Chemicals. Powdered CE-2 diet was used as the basal diet throughout the study. The experimental diets were prepared by mixing 5.0 and $10.0 \%$ FBRA with CE-2 diet. FBRA was supplied by Genmai Koso Co., Ltd. (Sapporo, Japan). Briefly, the manufacturing process of FBRA is as follows.
Fermentation base was made by steaming of brown rice and rice bran. Aspergillus Oryzae was then seeded to the fermentation base and fermentation process was continued for 18$24 \mathrm{~h}$. Subsequently, second fermentation was continued for additional $12-24 \mathrm{~h}$ for aging purpose. Fermented product was then dried and powdered. 4-(Methylnitrosamino)-1-(3-pyridyl)1-butanone (NNK) from Toronto Research Chemicals (Toronto, Canada), monoclonal rat anti-mouse Ki-67 antigen (Clone TEC-3), polyclonal rabbit anti-rat immunoglobulins/ biotinylated, polyclonal goat anti-rabbit immunoglobulins/ biotinylated, and Dako liquid DAB substrate-chromogen system were purchased from Dako Corp. A polyclonal affinitypurified rabbit antibody to the cleaved caspase-3 (Asp175) was obtained from Cell Signaling Technologies. Vectastain ${ }^{\circledR}$ Elite ABC Kit was purchased from Vector Laboratories.

Experimental procedure. The experimental design was approved by the Institutional Ethics Review Committee for animal experiments at the Gifu University. Six weeks of age of female A/J mice were randomly divided into 8 groups as shown in Fig. 1. Mice in groups 2 and 3 received 5 and $10 \%$ FBRA in diet, respectively, during initiation stage (during and until 1 week after NNK treatment) and then transferred to the control diet until 21 weeks of age. Mice in groups 4 and 5, which were maintained on basal diet during NNK treatment, received 5 and 10\% FBRA in diet, respectively, during the post-initiation stage (1 week after NNK treatment until 21 weeks of age). Mice in groups 7 and 8 received 5 and $10 \%$ FBRA in diet, respectively, throughout the experimental period. Mice in group 6 were maintained in control diet throughout the experimental period and served as nontreatment control. At 7 weeks of age, mice in groups 1-5 received the NNK (10 mmol) by i.p. injection. Fourteen weeks after NNK treatment, all surviving mice were sacrificed. Their lung were collected and weighted, infused with $10 \%$ neutral buffered formalin, and carefully inspected grossly. All of the macroscopically detected lung nodules were counted and examined histopathologically. Lung lesions, hyperplasias, and adenomas were diagnosed according to the criteria of 'International Classification of Rodent Tumors: The Mouse' (28). For Cyp2a5 level study, a total 10 female A/J mice were divided into 2 groups and received control diet and $10 \%$ FBRA in diet, respectively, at 6 weeks of age. Two weeks after FBRA treatment, all mice were sacrificed. Lung and liver tissues were collected for RNA isolation and quantitative analysis of Cyp2a5 expression.

RNA isolation and cDNA synthesis. Lung and liver tissue were cut off into small pieces ( $\sim 50-100 \mathrm{mg})$ and extracted the RNA by using TRIzol reagent (Invitrogen, Life Technologies, Carlsbad, CA, USA) and an RNeasy Mini Kit (Qiagen Corp., Hilden, Germany) according to the manufacturer's instructions. The amount and quality of RNA for each sample were assessed with the NanoDrop ${ }^{\circledR}$ ND-1000 UV-Vis Spectrophotometer (NanoDrop Technologies, Wilmington, DE, USA). Purified total RNA was reversetranscribed using the SuperScript First-Strand Synthesis System for the reverse transcriptase-polymerase chain reaction (RT-PCR) kit (Invitrogen), according to the manufacturer's protocol. 


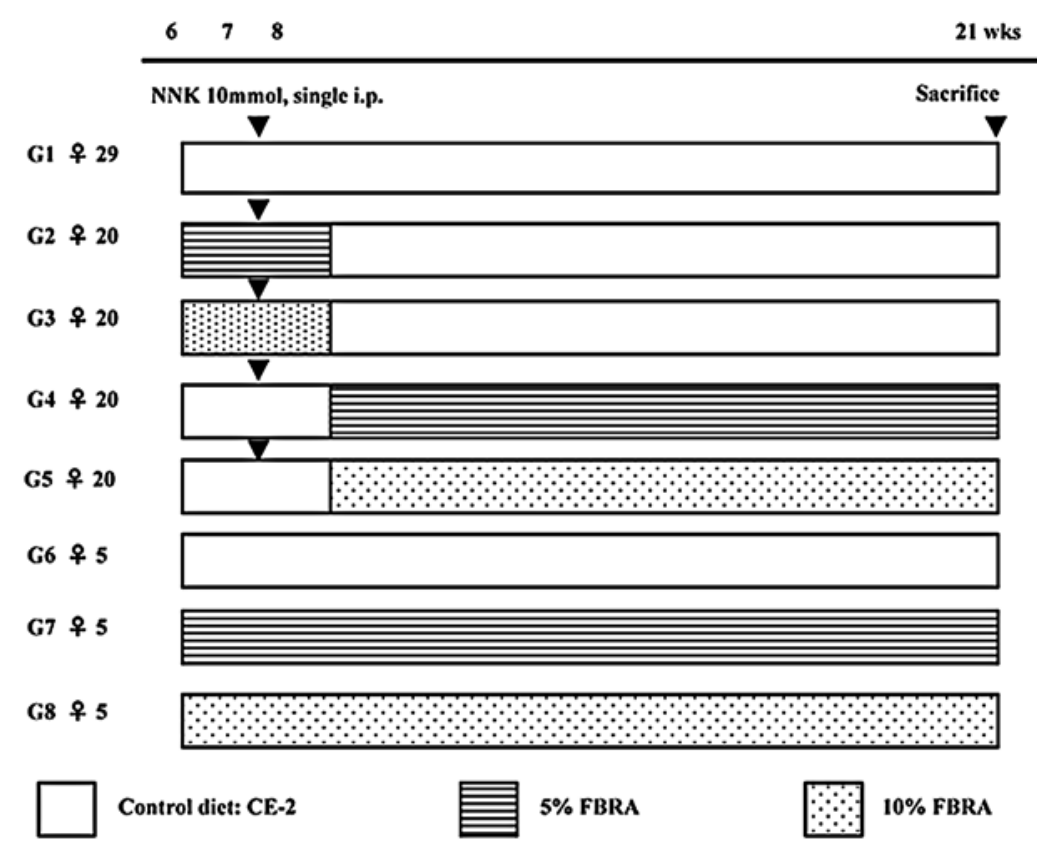

Figure 1. Experimental design to study the chemopreventive effect of the fermented brown rice and rice bran (FBRA) on NNK-induced lung tumorigenesis.

Real-time quantitative PCR (RT-PCR). Expression levels of CYP2A5 and $B$-actin mRNA were measured using a LightCycler (Roche Applied Science) and the specific sense and antisense primers. The reaction mixture contained $10.0 \mu \mathrm{l}$ of Takara SYBR Premix Ex Taq (Takara Bio Inc.), $1.0 \mu \mathrm{l}$ of $10 \mu \mathrm{M}$ of each primer, $3.0 \mu \mathrm{l}$ of distilled water and $5.0 \mu 1$ cDNA. The amplification number of cycles was 45 and the reaction took place for $10 \mathrm{sec}$ at $95^{\circ} \mathrm{C}, 10 \mathrm{sec}$ at $60^{\circ} \mathrm{C}$ and $6 \mathrm{sec}$ at $72^{\circ} \mathrm{C}$, with an initial step of $95^{\circ} \mathrm{C}$ for 10 min (hotstart). Oligonucleotide primers were the following: for CYP2A5, 5'-TGGTCCTGTATTCACCATCTACC-3' and 5'-ACTACG CCATAGCCTTTGAAAA-3'; for ß-actin, 5'-CATCCGTAA AGACCTCTATGCCAAC-3' and 5'-ATGGAGCCACCGAT CCACA-3'.

Immunohistochemistry. The avidin-biotin peroxidase complex $(\mathrm{ABC})$ technique was used for immunohistochemical studies. The lung whitish nodules ( size $\geq 0.8 \mathrm{~mm}$ ) from groups 1 and 5 were randomly collected. Sections $(5-\mu \mathrm{m}$ thick) were cut, deparaffinized, rehydrated in PBS, placed in $10 \mathrm{mmol} / \mathrm{l}$ citrate buffer ( $\mathrm{pH} \mathrm{6.0)}$, and heated in Pascal pressure cooker (Code No.S2800, Dako Corp.) programmed for $1 \mathrm{~min}$ at $120^{\circ} \mathrm{C}$ The endogenous peroxidase activity was blocked by incubation for $20 \mathrm{~min}$ in $3 \% \mathrm{H}_{2} \mathrm{O}_{2}$. After washing three times with PBS, the sections were preincubated with a normal blocking serum for $30 \mathrm{~min}$ at room temperature and then incubated with primary antibodies, which specific for Ki67 or cleaved caspase-3 (used at 1:100 dilution), overnight at $4{ }^{\circ} \mathrm{C}$. Subsequently, the section were incubated with biotinylated secondary antibodies (used at 1:250 dilution) for $30 \mathrm{~min}$ at room temperature, followed by incubation with avidin-coupled peroxidase (Vectastain Elite ABC Kit) for $30 \mathrm{~min}$ at room temperature. The sections were developed with 3,3V-diaminobenzidine (DAB), counterstained with hematoxylin and mounted coverslips.
Statistical analysis. The data for liver, kidney, lung or final body weights were analyzed by the Student's t-test. The incidence, multiplicity and size of lung proliferative lesions were analyzed by Student's t-test. Mouse CYP2A5 mRNA levels was analyzed by Mann-Whitney U-test. The Ki67 positive cell index was analyzed by Welch's t-test.

\section{Results}

Final body weight and weight of the liver, kidney and lung. During the 21 weeks of experimental period starting at week 6 , administration of FBRA caused no significant differences in final body weight and the weight of the liver, kidney or lung as shown in Table I. In addition, there were no clear signs of toxicity in the liver and kidney of any mice examined by the histological analysis.

Incidence, multiplicity and tumor size. Whitish nodules in the lung were frequently detected in mice treated with NNK. Only 1 mouse in the NNK-untreated group (group 7) harbored a nodule in the lung, suggesting a spontaneous development of lung tumor. There was no evidence of the development of lung tumors in groups 6 and 8. Histological analysis revealed that all lung lesions are adenomas (Fig. 2). The incidences and multiplicities (number of tumor per mice) of lung adenomas are summarized in Table II. The treatment of $10 \%$ FBRA (group 3) but not 5\% FBRA (group 2) during the initiation phase significantly reduced the multiplicity of lung tumor when compared with control diet group 1 ( $\mathrm{p}<0.006)$. However, 10\% FBRA had no effects for the incidence and tumor's size in comparison with group 1 as shown in Table II. The treatment of $10 \%$ FBRA during the post-initiation phase also significantly decreased in both the multiplicity and tumor size in comparison with group $1(\mathrm{p}<0.04)$ but not incidence of lung tumor induced by NNK (Table II). 
Table I. Final body weight and the weight of liver, kidney and lung.

\begin{tabular}{|c|c|c|c|c|c|c|}
\hline \multirow[b]{2}{*}{ Group } & \multirow[b]{2}{*}{ Treatment } & \multirow[b]{2}{*}{ No. ${ }^{b}$} & \multicolumn{4}{|c|}{ Weight $(g)^{\mathrm{a}}$} \\
\hline & & & Body & Liver & Kidney & Lung \\
\hline 1 & NNK alone & 26 & $25.7 \pm 3.0$ & $1.21 \pm 0.13$ & $0.40 \pm 0.04$ & $0.21 \pm 0.04$ \\
\hline 2 & $5 \%$ FBRA (initiation) + NNK & 20 & $29.1 \pm 4.2$ & $1.22 \pm 0.15$ & $0.42 \pm 0.07$ & $0.22 \pm 0.03$ \\
\hline 3 & $10 \%$ FBRA (initiation) + NNK & 20 & $26.9 \pm 4.2$ & $1.32 \pm 0.16$ & $0.42 \pm 0.07$ & $0.23 \pm 0.02$ \\
\hline 4 & $5 \%$ FBRA (post-initiation) + NNK & 20 & $28.0 \pm 2.8$ & $1.23 \pm 0.17$ & $0.43 \pm 0.08$ & $0.21 \pm 0.04$ \\
\hline 5 & $10 \%$ FBRA (post-initiation) + NNK & 20 & $28.6 \pm 3.6$ & $1.18 \pm 0.14$ & $0.42 \pm 0.09$ & $0.21 \pm 0.02$ \\
\hline 6 & Control diet alone & 5 & $28.0 \pm 4.2$ & $1.27 \pm 0.14$ & $0.44 \pm 0.07$ & $0.23 \pm 0.02$ \\
\hline 7 & $5 \%$ FBRA alone & 5 & $29.6 \pm 1.5$ & $1.41 \pm 0.07$ & $0.49 \pm 0.02$ & $0.22 \pm 0.01$ \\
\hline 8 & $10 \%$ FBRA alone & 5 & $26.1 \pm 1.8$ & $1.30 \pm 0.08$ & $0.42 \pm 0.04$ & $0.23 \pm 0.01$ \\
\hline
\end{tabular}

${ }^{\mathrm{a}}$ Mean $\pm \mathrm{SD} .{ }^{\mathrm{b}}$ Number of mice examined.

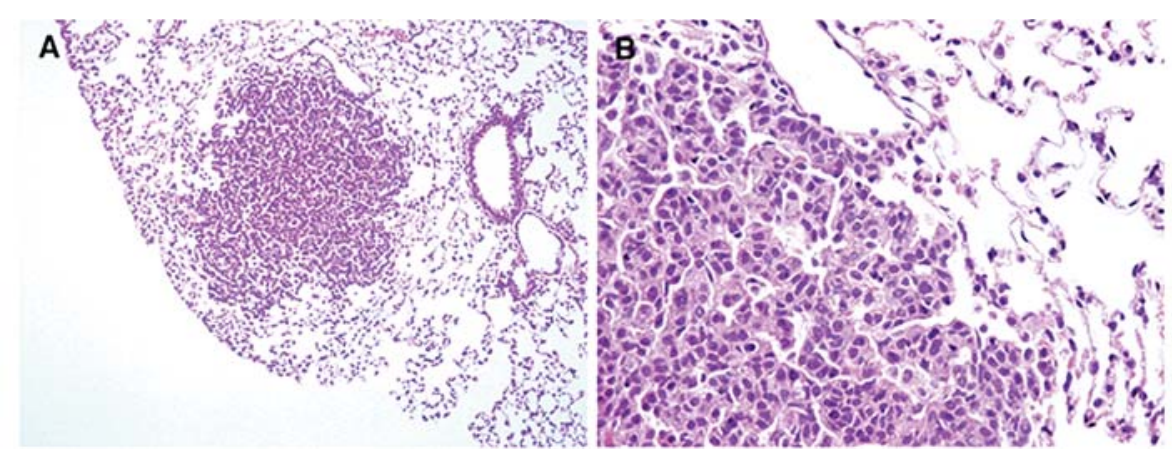

Figure 2. Histopathology of lung adenoma induced by NNK. Photomicrograph of an H\&E stained mouse lung adenoma from group 1 at x100 and x400 magnification, respectively.

Table II. Incidences and multiplicities of NNK-induced lung adenomas in female A/J mice treated with FBRA.

\begin{tabular}{|c|c|c|c|c|c|}
\hline Group & Treatment & No. ${ }^{a}$ & Incidence $(\%)^{\mathrm{b}}$ & Multiplicity $^{\mathrm{c}}$ & Tumor size $^{\mathrm{d}}$ \\
\hline 1 & NNK alone & 26 & $26 / 26(100)$ & $4.08 \pm 1.85$ & $0.77 \pm 0.33$ \\
\hline 2 & $5 \%$ FBRA (initiation) + NNK & 20 & $19 / 20 \quad(95)$ & $3.60 \pm 2.44$ & $0.78 \pm 0.33$ \\
\hline 3 & $10 \%$ FBRA (initiation) + NNK & 20 & $16 / 20 \quad(80)$ & $2.35 \pm 2.13^{\mathrm{e}}$ & $0.78 \pm 0.32$ \\
\hline 4 & $5 \%$ FBRA (post-initiation) + NNK & 20 & $20 / 20(100)$ & $3.10 \pm 1.59$ & $0.74 \pm 0.30$ \\
\hline 5 & $10 \%$ FBRA (post-initiation) + NNK & 20 & $20 / 20(100)$ & $3.00 \pm 1.52^{\mathrm{f}}$ & $0.66 \pm 0.32^{\mathrm{g}}$ \\
\hline 6 & Control diet alone & 5 & $0 / 5$ & $0.00 \pm 0.00$ & $\mathrm{ND}^{\mathrm{h}}$ \\
\hline 7 & $5 \%$ FBRA alone & 5 & $1 / 5 \quad(20)$ & $0.20 \pm 0.45$ & ND \\
\hline 8 & $10 \%$ FBRA alone & 5 & $0 / 5$ & $0.00 \pm 0.00$ & ND \\
\hline
\end{tabular}

${ }^{\mathrm{a} N u m b e r}$ of mice examined. ${ }^{\mathrm{b}}$ Number of mice observed each lesion (\%). ${ }^{\mathrm{c}}$ Tumor per mouse (mean $\left.\pm \mathrm{SD}\right) .{ }^{\mathrm{d}} \mathrm{Mean} \pm \mathrm{SD}\left(\mathrm{mm}{ }^{2}\right) .{ }^{\mathrm{e}} \mathrm{Significantly}$

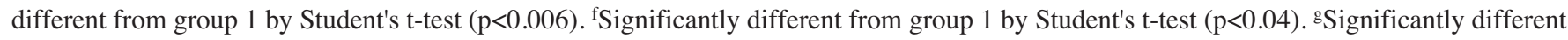
from group 1 by Student's t-test $(\mathrm{p}<0.04)$. ${ }^{\text {hND }}$, not determined.

Expression levels of Cyp2a5 mRNA in liver and lung. To investigate the molecular mechanisms of the suppressing effect of FBRA against NNK-induced lung tumorigenesis in the initiation phase, the mRNA expression levels of Cyp2a5 in both liver and lung tissues was analyzed by quantitative RT-PCR. Data for relative-quantification of Cyp2a5 mRNA in liver and lung of FBRA-treated A/J mice are summarized in Fig. 3. Administration of $10 \%$ FBRA led to the decreased 

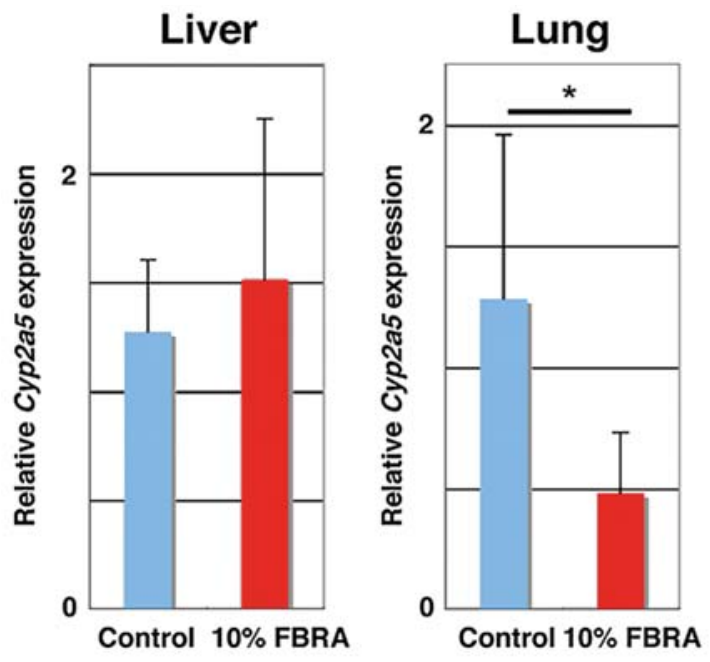

Figure 3. Quantitative real-time PCR (qRT-PCR) analyses of mouse Cyp2a5 mRNA in the liver and lung. Data are mean \pm SD values, normalized with respect to $\beta$-actin.

expression levels of Cyp2a5 mRNA in the lung $(0.48 \pm 0.25$ in FBRA treated mice vs. $1.28 \pm 0.68$ in the control mice, $\mathrm{p}<0.02)$ but not in the liver $(1.51 \pm 0.74$ in FBRA-treated mice vs. $1.27 \pm 0.33$ in the control mice).

Cell proliferative and apoptotic indices in lung tumors. In this study, suppressive effect of FBRA was confirmed not only in the initiation phase, but also in the post-initiation phase. Thus, cell kinetic analysis for cell proliferative and apoptotic index of lung tumors was performed with the expression of Ki67 and cleaved caspase-3. Administration of 10\% FBRA to NNK-treated mice significantly decreased Ki67 positive cell index in the lung adenomas when compared with the adenomas in the NNK-treated group with control diet alone $(0.065 \pm 0.016$ and $0.114 \pm 0.025$ per field at $x 400$ magnification, respectively, $\mathrm{p}<0.001)$. In contrast to the frequent expression of positive cells for the cleaved caspase- 3 in the control section of the colon, positive cells were scarcely found in NNK-induced lung tumors from different groups, indicating that cellular apoptosis rarely occurs in such tumors (data not shown).

\section{Discussion}

It is widely recognized that cigarette smoke contains a number of carcinogens, tumor initiators, promoters, co-carcinogens and mutagens. The mutagenicity of many constituents in tobacco smoke has been demonstrated in a variety of prokaryotic and eukaryotic test systems. The carcinogenicity of some of these mutagens has been evaluated in animals; some of these compounds are already designated as human carcinogens. 4-(Methylnitrosamino)-1-(3-pyridyl)-1-butanone (NNK) is one of the major carcinogenic compounds in cigarette smoke. Several epidemiological studies have suggested that NNK is one of the important causative agents for human lung cancers (2-5).

It is assumed that dietary factors play an important role in the prevention of several types of cancer, including lung cancer. A number of reports have shown the chemopreventive effect of fermented brown rice and rice bran (FBRA) on several types of cancer $(22,24-26)$. The data presented herein also demonstrate that the exposure of $10 \%$ FBRA in the diet during both initiation and post-initiation phase significantly suppressed occurrence of the total number of lung proliferative lesions of NNK-treated A/J mice. In this study, the administration of $10 \%$ FBRA in the post-initiation phase significantly decreased the mean size of tumor. This inhibitory action is consistent with the previous reports that FBRA inhibited the carcinogenesis of the colon, liver, stomach, bladder and esophagus (22-26).

It is known that absorbed NNK initially exist in the body as a procarcinogen, an inert form that requires activation to exert its full effects. There are three primary pathways with regard to NNK activation: i) carbonyl reduction, ii) pyridine $\mathrm{N}$-oxidation and iii) $\alpha$-hydroxylation $(5,29,30)$. Cytochrome pigment 450 (CYP450) enzymes belonging to the CYP multigene family catalyze the $\alpha$-hydroxylation of NNK in the
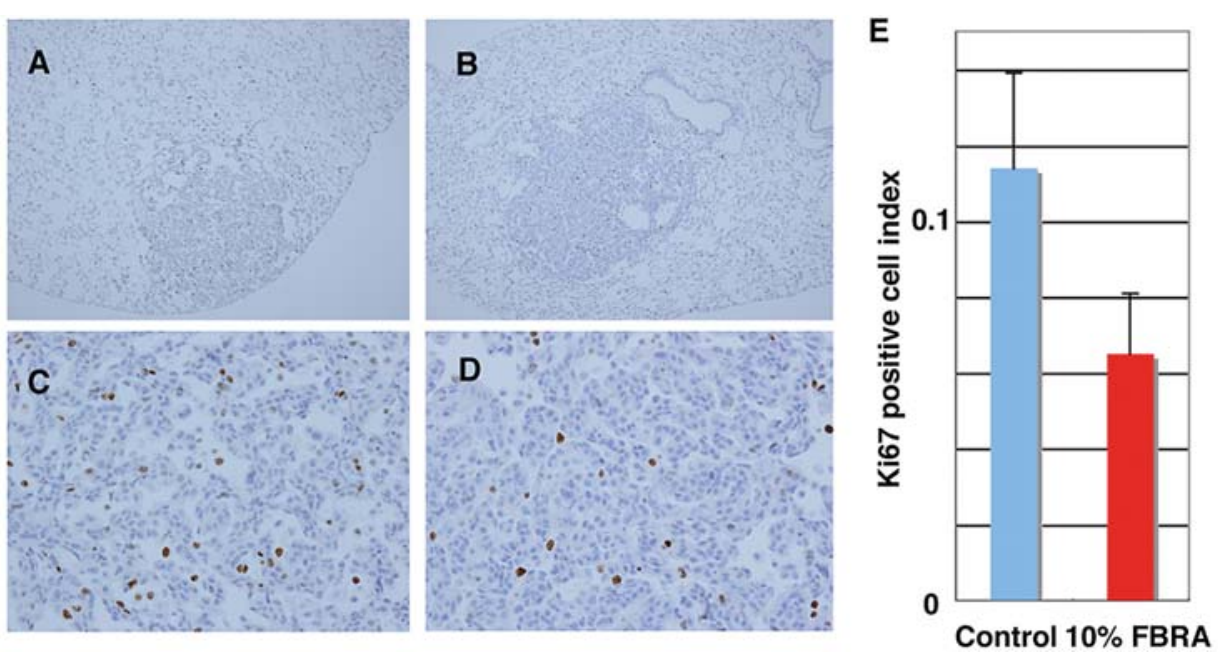

Figure 4. Immunohistochemical examination for the expression of Ki67 in lung adenoma induced by NNK. (A and C) Display lung adenoma from control diet group (group 1) at x100 and x400 magnification, respectively. (B and D) Lung adenoma from $10 \%$ FBRA group (group 5) at x100 and x400 magnification, respectively. Ki67 positive cell index \pm SD is shown $(\mathrm{E})$. 
oxidative metabolism pathway $(5,9,11)$. It is noteworthy that expression levels of Cyp2a5 were significantly decreased by the administration of FBRA in this study. It is possible that the inhibitory effect on the Cyp2a5 expression leads to a decreased production of the active form of NNKs such as $\alpha$ hydroxyNNKs and $\alpha$-hydroxyNNALs, and is associated with the suppressive effects of FBRA on the lung tumorigenesis at the initiation phase.

In general, hyperproliferation is suggested to be relevant to carcinogenesis of many organs (31-33). Indeed, carcinomas of the lung have the highest indices for Ki67 (34,35). Therefore, the control of cell proliferation in the target organs is regarded as an important strategy for chemoprevention. Presently, we showed that dietary exposure of FBRA during the post-initiation phase decreased the size of tumors. It is important that the number of Ki67 positive cells in lung adenomas was significantly decreased by the post-initiation treatment of FBRA. Similar results have been obtained in other studies with various chemopreventive agents $(36,37)$ and FBRA (24). The suppression of proliferative activity in tumor cells might be one of the important mechanisms of the chemopreventive effect of FBRA at post-initiation phase.

FBRA is a processed food prepared by fermenting brown rice and rice bran with Aspergillus Oryzae. The nutritional and sanitary advantage of fermentation has been recognized, although the details are not well known. Fermented soy bean paste or soy sauce, which prepared by fermenting with Aspergillus Oryzae, has been found to be more stable against lipid peroxidation than unfermented soybeans, because Aspergillus Oryzae-fermented soybean products contain several antioxidants like 6-hydroxydaidzein, 8-hydroxydaidzein and 8-hydroxygenistein more abundantly than unfermented soybeans (38). These 8-hydroxyisiflavones are reported to possess greater 1,1-diphenyl-2-picrylhydrazyl (DPPH) radicalscavenging activity and antiproliferative activity than the corresponding isoflavone analogs $(38,39)$. Furthermore, such 8-hydroxyisoflavones and 6-hydroxydaidzein are reported to possess antimutagenic activity $(39,40)$. Several epidemiological and preclinical studies suggested the chemopreventive effects of such fermented soybean products (41-43). Dihydroferulic acid and dihydrosinapic acid, which were isolated from unpolished rice vinegar (Kurosu), were suggested as the major constituents responsible for radical scavenging activity of Kurosu (44). These acids are produced in Kurosu through the process of the fermentation from ferulic acid and sinapic acid. Rice bran contains approximately $20 \%$ oil which contains several bioactive polyphenols including ferulic acid, protocatechuic acid, sinapic acid and vanillic acid (45). Thus, it is possible that FBRA has similar mechanistic aspects to the fermented soybeans or Kurosu.

In conclusion, we demonstrated that administration of fermented brown rice and rice bran (FBRA) during both the initiation and post-initiation phase inhibits lung tumorigenesis induced by NNK in female A/J mice, indicating that FBRA is a promising chemopreventive agent for human lung cancer. Our results suggest that a reduction of Cyp2a5 mRNA expression levels and a reduction of cell proliferative activity in tumor cells may be involved in such chemopreventive effects of FBRA.

\section{Acknowledgements}

We wound like to thank Ms. Kyoko Takahashi for technical assistance, Mr. Yoshitaka Kinjo for animal care. This study was supported by a Grant-in-Aid from Ministry of Education, Culture, Sports, Science and Technology and Grant-in-Aid from Ministry of Health, Labour and Welfare of Japan.

\section{References}

1. Parkin DM, Bray F, Ferlay J and Pisani P: Global cancer statistics, 2002. CA Cancer J Clin 55: 74-108, 2005.

2. Hecht SS: Tobacco smoke carcinogens and lung cancer. J Natl Cancer Inst 91: 1194-1210, 1999.

3. Loeb LA, Ernster VL, Warner KE, Abbotts J and Laszlo J: Smoking and lung cancer: an overview. Cancer Res 44: 5940-5958, 1984

4. Hecht SS: Biochemistry, biology, and carcinogenicity of tobaccospecific N-nitrosamines. Chem Res Toxicol 11: 559-603, 1998.

5. Akopyan G and Bonavida B: Understanding tobacco smoke carcinogen NNK and lung tumorigenesis. Int J Oncol 29: 745-752, 2006.

6. Wang Y, Zhang Z, Yan Y, Lemon WJ, La Regina M, Morrison C, Lubet R and You M: A chemically induced model for squamous cell carcinoma of the lung in mice: histopathology and strain susceptibility. Cancer Res 64: 1647-1654, 2004.

7. Malkinson AM: Primary lung tumors in mice: an experimentally manipulable model of human adenocarcinoma. Cancer Res 52: S2670-S2676, 1992.

8. Pulling LC, Vuillemenot BR, Hutt JA, Devereux TR and Belinsky SA: Aberrant promoter hypermethylation of the deathassociated protein kinase gene is early and frequent in murine lung tumors induced by cigarette smoke and tobacco carcinogens. Cancer Res 64: 3844-3848, 2004.

9. Isin EM and Guengerich FP: Complex reactions catalyzed by cytochrome P450 enzymes. Biochim Biophys Acta 1770: 314-329, 2007.

10. Jalas JR, Ding X and Murphy SE: Comparative metabolism of the tobacco-specific nitrosamines 4-(methylnitrosamino)-1-(3pyridyl)-1-butanone and 4-(methylnitrosamino)-1-(3-pyridyl)-1butanol by rat cytochrome P450 $2 \mathrm{~A} 3$ and human cytochrome P450 2A13. Drug Metab Dispos 31: 1199-1202, 2003.

11. Kamataki T, Fujita K, Nakayama K, Yamazaki Y, Miyamoto M and Ariyoshi N: Role of human cytochrome P450 (CYP) in the metabolic activation of nitrosamine derivatives: application of genetically engineered Salmonella expressing human CYP. Drug Metab Rev 34: 667-676, 2002.

12. Nakajima M, Yamamoto T, Nunoya K, Yokoi T, Nagashima K, Inoue K, Funae Y, Shimada N, Kamataki T and Kuroiwa Y: Role of human cytochrome P4502A6 in C-oxidation of nicotine. Drug Metab Dispos 24: 1212-1217, 1996.

13. Ariyoshi N, Miyamoto M, Umetsu Y, Kunitoh H, DosakaAkita H, Sawamura Y, Yokota J, Nemoto N, Sato K and Kamataki T: Genetic polymorphism of CYP2A6 gene and tobacco-induced lung cancer risk in male smokers. Cancer Epidemiol Biomarkers Prev 11: 890-894, 2002.

14. Fujieda M, Yamazaki H, Saito T, Kiyotani K, Gyamfi MA, Sakurai M, Dosaka-Akita H, Sawamura Y, Yokota J, Kunitoh H and Kamataki T: Evaluation of CYP2A6 genetic polymorphisms as determinants of smoking behavior and tobaccorelated lung cancer risk in male Japanese smokers. Carcinogenesis 25: 2451-2458, 2004.

15. Lindberg R, Burkhart B, Ichikawa T and Negishi M: The structure and characterization of type I P-450(15) alpha gene as major steroid 15 alpha-hydroxylase and its comparison with type II P-450(15) alpha gene. J Biol Chem 264: 6465-6471, 1989.

16. Taniguchi H, Hosoda A, Tsuno T, Maruta Y and Nomura E: Preparation of ferulic acid and its application for the synthesis of cancer chemopreventive agents. Anticancer Res 19: 3757-3761, 1999.

17. Graf E, Empson KL and Eaton JW: Phytic acid. A natural antioxidant. J Biol Chem 262: 11647-11650, 1987.

18. Xu Z, Hua N and Godber JS: Antioxidant activity of tocopherols, tocotrienols, and gamma-oryzanol components from rice bran against cholesterol oxidation accelerated by $2,2^{2}$-azobis(2methylpropionamidine) dihydrochloride. J Agric Food Chem 49: 2077-2081, 2001. 
19. Van Rensburg SJ, Hall JM and Du Bruyn DB: Effects of various dietary staples on esophageal carcinogenesis induced in rats by subcutaneously administered N-nitrosomethylbenzylamine. J Natl Cancer Inst 75: 561-566, 1985.

20. Kawabata K, Yamamoto T, Hara A, Shimizu M, Yamada Y, Matsunaga K, Tanaka T and Mori H: Modifying effects of ferulic acid on azoxymethane-induced colon carcinogenesis in F344 rats. Cancer Lett 157: 15-21, 2000.

21. Tanaka T, Kojima T, Kawamori T, Wang A, Suzui M, Okamoto K and Mori $\mathrm{H}$ : Inhibition of 4-nitroquinoline-1-oxide-induced rat tongue carcinogenesis by the naturally occurring plant phenolics caffeic, ellagic, chlorogenic and ferulic acids. Carcinogenesis 14: $1321-1325,1993$.

22. Katyama M, Yoshimi N, Yamada Y, Sakata K, Kuno T, Yoshida K, Qiao Z, Vihn PQ, Iwasaki T, Kobayashi H and Mori $\mathrm{H}$ : Preventive effect of fermented brown rice and rice bran against colon carcinogenesis in male F344 rats. Oncol Rep 9: 817-822, 2002

23. Katayama M, Sugie S, Yoshimi N, Yamada Y, Sakata K, Qiao Z, Iwasaki T, Kobayashi $\mathrm{H}$ and Mori $\mathrm{H}$ : Preventive effect of fermented brown rice and rice bran on diethylnitrosoamine and phenobarbital-induced hepatocarcinogenesis in male F344 rats. Oncol Rep 10: 875-880, 2003.

24. Tomita H, Kuno T, Yamada Y, Oyama T, Asano N, Miyazaki Y, Baba S, Taguchi A, Hara A, Iwasaki T, Kobayashi H and Mori H: Preventive effect of fermented brown rice and rice bran on $\mathrm{N}$ methyl-N'-nitro-N-nitrosoguanidine-induced gastric carcinogenesis in rats. Oncol Rep 19: 11-15, 2008.

25. Kuno T, Hirose Y, Hata K, Kato K, Qiang SH, Kitaori N, Hara A, Iwasaki T, Yoshimura T, Wada K, Kobayashi $\mathrm{H}$ and Mori H Preventive effect of fermented brown rice and rice bran on $\mathrm{N}$-nitrosomethylbenzylamine-induced esophageal tumorigenesis in rats. Int J Oncol 25: 1809-1815, 2004.

26. Kuno T, Hirose Y, Yamada Y, Hata K, Qiang SH, Asano N, Oyama T, Zhi H, Iwasaki T, Kobayashi H and Mori H: Chemoprevention of mouse urinary bladder carcinogenesis by fermented brown rice and rice bran. Oncol Rep 15: 533-538, 2006.

27. Tazawa K, Naoko F and Hirohide N: Superoxide scavenging effect of fermented brown rice determined by ESR spin-trapping method (in Japanese). Food Style 3: 32-37, 1999.

28. Dungworth D, Rittinghansen S, Schwarz L, Harkema J, Hayashi Y and Kittel B: Respiratory system and mesothelium. In: International Classification of Rodent Tumors: The Mouse. Springer, Berlin, pp87-138, 2001.

29. Wiener D, Doerge DR, Fang JL, Upadhyaya P and Lazarus P: Characterization of $\mathrm{N}$-glucuronidation of the lung carcinogen 4-(methylnitrosamino)-1-(3-pyridyl)-1-butanol (NNAL) in human liver: importance of UDP-glucuronosyltransferase 1A4. Drug Metab Dispos 32: 72-79, 2004.

30. Tulunay OE, Hecht SS, Carmella SG, Zhang Y, Lemmonds C Murphy S and Hatsukami DK: Urinary metabolites of a tobaccospecific lung carcinogen in non-smoking hospitality workers. Cancer Epidemiol Biomarkers Prev 14: 1283-1286, 2005.

31. Bacchi CE and Gown AM: Detection of cell proliferation in tissue sections. Braz J Med Biol Res 26: 677-687, 1993.

32. Rindi G, D'Adda T, Froio E, Fellegara G and Bordi C: Prognostic factors in gastrointestinal endocrine tumors. Endocr Pathol 18: 145-149, 2007.
33. Van Diest PJ, van der Wall E and Baak JP: Prognostic value of proliferation in invasive breast cancer: a review. J Clin Pathol 57: 675-681, 2004.

34. Gatter KC, Dunnill MS, Gerdes J, Stein H and Mason DY: New approach to assessing lung tumours in man. J Clin Pathol 39: 590-593, 1986.

35. Soomro IN and Whimster WF: Growth fraction in lung tumours determined by Ki67 immunostaining and comparison with AgNOR scores. J Pathol 162: 217-222, 1990.

36. D'Ambrosio SM, Gibson-D'Ambrosio RE, Wani G, Casto B Milo GE, Kelloff GJ and Steele VE: Modulation of Ki67, p53 and RARbeta expression in normal, premalignant and malignant human oral epithelial cells by chemopreventive agents. Anticancer Res 21: 3229-3235, 2001.

37. Ferrandina G, Ranelletti FO, Legge F, Lauriola L, Salutari V, Gessi M, Testa AC, Werner U, Navarra P, Tringali G, Battaglia A and Scambia G: Celecoxib modulates the expression of cyclooxygenase-2, ki67, apoptosis-related marker, and microvessel density in human cervical cancer: a pilot study. Clin Cancer Res 9: 4324-4331, 2003.

38. Esaki H, Kawakishi S, Morimitsu Y and Osawa T: New potent antioxidative o-dihydroxyisoflavones in fermented Japanese soybean products. Biosci Biotechnol Biochem 63: 1637-1639, 1999.

39. Hirota A, Taki S, Kawaii S, Yano M and Abe N: 1,1-Diphenyl2-picrylhydrazyl radical-scavenging compounds from soybean miso and antiproliferative activity of isoflavones from soybean miso toward the cancer cell lines. Biosci Biotechnol Biochem 64: 1038-1040, 2000

40. Chen YC, Inaba M, Abe N and Hirota A: Antimutagenic activity of 8-hydroxyisoflavones and 6-hydroxydaidzein from soybean miso. Biosci Biotechnol Biochem 67: 903-906, 2003.

41. Ohta T, Nakatsugi S, Watanabe K, Kawamori T, Ishikawa F, Morotomi M, Sugie S, Toda T, Sugimura T and Wakabayashi K: Inhibitory effects of Bifidobacterium-fermented soy milk on 2amino-1-methyl-6-phenylimidazo[4,5-b]pyridine-induced rat mammary carcinogenesis, with a partial contribution of its component isoflavones. Carcinogenesis 21: 937-941, 2000.

42. Fukutake M, Takahashi M, Ishida K, Kawamura H, Sugimura T and Wakabayashi K: Quantification of genistein and genistin in soybeans and soybean products. Food Chem Toxicol 34: 457-461, 1996.

43. Zhou JR, Yu L, Zhong Y and Blackburn GL: Soy phytochemicals and tea bioactive components synergistically inhibit androgen-sensitive human prostate tumors in mice. J Nutr 133: 516-521, 2003.

44. Shimoji Y, Tamura Y, Nakamura Y, Nanda K, Nishidai S, Nishikawa Y, Ishihara N, Uenakai K and Ohigashi H: Isolation and identification of DPPH radical scavenging compounds in Kurosu (Japanese unpolished rice vinegar). J Agric Food Chem 50: 6501-6503, 2002

45. Hudson EA, Dinh PA, Kokubun T, Simmonds MS and Gescher A: Characterization of potentially chemopreventive phenols in extracts of brown rice that inhibit the growth of human breast and colon cancer cells. Cancer Epidemiol Biomarkers Prev 9: 1163-1170, 2000. 